\title{
The influence of RCA addition on selected parameters of concrete
}

\author{
Roman Jaskulski ${ }^{1, *}$, Marcin Supera ${ }^{1}$, Wojciech Kubissa ${ }^{1}$, Peter Koteš ${ }^{2}$, Miroslav Brodňan ${ }^{2}$ \\ ${ }^{1}$ Warsaw University of Technology, Faculty of Civil Engineering, Mechanics and Petrochemistry, \\ Łukasiewicza 17, 09-402 Płock, Poland \\ ${ }^{2}$ University of Žilina, Univerzitna 1, 01026 Žilina, Slovakia
}

\begin{abstract}
The main goal of this research was to evaluate the effects of using recycled concrete aggregate (RCA) of an average quality as a $50 \%$ replacement for natural coarse aggregate. A total of 26 concrete mixtures were prepared, 13 containing RCA as a $50 \%$ of coarse aggregate and the same number of mixes only with natural aggregate (NA). The results show the influence of the RCA incorporation on concretes for the same $\mathrm{w} / \mathrm{c}$ ratio. Both mechanical and durability parameters of the concretes made with recycled aggregate are worse, and the differences increase for low w/c ratio. Despite the reduction of these parameters in relation to concretes with only NA, both mechanical and durability test results obtained for concrete series with RCA can be described as good.
\end{abstract}

\section{Introduction}

Concrete is the most popular building material. One of the main reasons is because it is quite easy to prepare and the ingredients for concrete production - aggregate, water and cement are easy to obtain. However, the depletion of natural resources is becoming increasingly problematic so the trend for substitution of basic concrete components by more sustainable materials can be observed. Replacing part of the cement by supplementary cementing materials such as fly ash or blast furnace slag is now commonplace [1-3]. The aggregate takes up most of concrete volume - about $70 \%$. The wider use of recycled concrete aggregate (RCA) for production of concrete may be the answer for natural aggregate depletion [4].

Despite that using RCA as natural aggregate (NA) substitute may be currently still more expensive than using NA, it should be noted that exhaustion mentioned above results in the necessity of bringing aggregate from more distant places - so as a result production costs will be still increasing [5,6]. It is estimated that in Europe alone less than 4 billion tons of aggregate were extracted in 2015 [7].

Concrete rubble is the most common type of construction waste, which is usually not recycled, but mostly stored [8]. It would seem natural to use concrete rubble as an aggregate for the new concrete. Despite the growing amount of research on the use of RCA

\footnotetext{
* Corresponding author: Roman.Jaskulski@.pw.edu.pl
} 
in the production of concrete, manufacturers concerns about the strength and durability of the concrete made with RCA because its use is still rare. The European standard EN 206 allows the use of recycle aggregate in an amount greater than $30 \%$ only in the case of the exposure class X0. Many authors, however, show that concrete with RCA in a higher than the above mentioned amount, despite worse properties than analogous concrete with NA only, can still have good mechanical properties as well as those that provide durability of the structure $[9,10]$. Some authors proved that by using high-quality coarse RCA as only coarse aggregate, concrete with negligible effects of RCA incorporation may be obtained [11]. Additional superplasticizer usage for this concrete allow to obtain better mechanical and durability properties such as compressive and tensile strength, water absorption, shrinkage, chloride diffusion coefficient and carbonation depth in comparison to reference concrete on natural aggregate. As part of this work, in-situ constructions were also made using tested concrete to investigate some ductility parameters, collapse mechanism and deformations. Studies on these constructions have shown that the use of concrete in structures together with reinforcement steel reduces the negative effects of RCA use. Common calculation methods and reinforcement detailing allows to effectively predict the behaviour of the structure in which concrete with RCA was used as good as those where only NA was used. Attempts are also made to estimate certain properties of concrete with the use of RCA using mathematical models based on experimental results $[12,13]$. The results of the attempts are ambiguous.

Some researchers indicate that by using concrete additives such as silica fume or metakaolin, high performance concrete can be made from RCA that constitutes up to $100 \%$ of the coarse fraction [14-16]. It should be noted that the actual use of a RCA in industry would involve a certain degree of carbonation of this aggregate, which is often not included in the research. Few works also take into account this factor, and the authors show a positive effect of aggregate carbonation on selected properties of both concrete and mortar $[17,18]$. Besides requirements of mechanical strength and durability, many constructions should have good thermal insulation properties. Investigations on the thermal properties of concrete with RCA show that due to the content of the original mortar in RCA, concrete made with that aggregate is characterized by smaller thermal conductivity then for concrete with only natural aggregate. That shows, that RCA can be good ecological material for example for concrete blocks production [19,20].

The aim of the research was to compare some mechanical and durability properties of concrete in which as the $50 \%$ of coarse aggregate the medium-quality RCA was used with the corresponding concrete only for NA. The thesis that the use of RCA in such proportions would generate a slight reduction of these parameters was verified.

\section{Materials and methods}

\subsection{Materials}

Twenty six concrete mixtures were prepared of which 13 containing RCA as a $50 \%$ of coarse aggregate (denoted as $\mathrm{Rx}$, where " $\mathrm{x}$ " indicates the number of series) and the same number of mixes only with natural aggregate (denoted as Nx). The subsequent numbers of the $\mathrm{R}$ and $\mathrm{N}$ series are their equivalents.

Portland cement CEM II/B-V 32,5R from Ożarów Cement Plant as per PN-EN 197-1 was used. The water used to make concrete was tap water, which fulfilled the requirements of PN-EN 1008. As natural fine aggregate river quartz sand was used and gravel as coarse aggregate. RCA was obtained by crushing in laboratory jaw crusher concrete specimens of average compressive strength in range $35-50 \mathrm{MPa}$, at the age of 1 to 4 years. The 
specimens were remaining after strength tests and were stored outside. The aggregate was sieved to obtain $4-16 \mathrm{~mm}$ fraction. Fractions below $4 \mathrm{~mm}$ due to the large amount of dust and mortar particles were not used.

Prepared mixes contained from 200 to $500 \mathrm{~kg} / \mathrm{m}^{3}$ of cement and their w/c ratio was in range from 0.4 to 0.8 . As mentioned before, the mass share of RCA in the $4-16 \mathrm{~mm}$ fraction was $50 \%$. The remaining part of this fraction was gravel. Because RCA absorbs water from the mixture, additional water in the amount of 5\% of RCA mass was added to concrete mixes. This part of water was not included in the assumed w/c ratio. Mix proportions are presented in the Tables 1 and 2. Due to problems with consistency of the concrete mixture $\mathrm{N} 10$, plasticizer in amount of $0.5 \%$ of cement mass was used.

Table 1. R-Series mix proportions $\left(\mathrm{kg} / \mathrm{m}^{3}\right)$

\begin{tabular}{|l|c|c|c|c|c|c|c|c|c|c|c|c|c|}
\hline $\begin{array}{l}\text { Mix } \\
\text { designation/ } \\
\text { Component }\end{array}$ & R1 & $\mathbf{R 2}$ & $\mathbf{R 3}$ & $\mathbf{R 4}$ & $\mathbf{R 5}$ & $\mathbf{R 6}$ & $\mathbf{R 7}$ & $\mathbf{R 8}$ & $\mathbf{R 9}$ & $\mathbf{R 1 0}$ & $\mathbf{R 1 1}$ & $\mathbf{R 1 2}$ & $\mathbf{R 1 3}$ \\
\hline Cement & 200 & 250 & 200 & 250 & 400 & 500 & 400 & 250 & 300 & 300 & 400 & 200 & 294 \\
\hline Sand & 728 & 675 & 747 & 699 & 630 & 553 & 668 & 722 & 679 & 707 & 592 & 766 & 722 \\
\hline Gravel & 631 & 585 & 647 & 605 & 546 & 479 & 578 & 626 & 588 & 613 & 513 & 663 & 625 \\
\hline RCA & 631 & 585 & 647 & 605 & 546 & 479 & 578 & 626 & 588 & 613 & 513 & 663 & 625 \\
\hline Water & 192 & 229 & 172 & 205 & 227 & 274 & 189 & 181 & 209 & 181 & 266 & 153 & 168 \\
\hline w/c & 0.8 & 0.8 & 0.7 & 0.7 & 0.5 & 0.5 & 0.4 & 0.6 & 0.6 & 0.5 & 0.6 & 0.6 & 0.47 \\
\hline
\end{tabular}

Table 2. N-series mix proportions $\left(\mathrm{kg} / \mathrm{m}^{3}\right)$

\begin{tabular}{|l|c|c|c|c|c|c|c|c|c|c|c|c|c|}
\hline $\begin{array}{l}\text { Mix } \\
\text { designation/ } \\
\text { Component }\end{array}$ & N1 & N2 & N3 & N4 & N5 & N6 & N7 & N8 & N9 & N10 & N11 & N12 & N13 \\
\hline Cement & 200 & 250 & 200 & 250 & 400 & 500 & 400 & 250 & 300 & 300 & 400 & 200 & 300 \\
\hline Sand & 667 & 619 & 684 & 640 & 577 & 506 & 612 & 662 & 622 & 648 & 543 & 701 & 656 \\
\hline $\begin{array}{l}\text { Gravel } \\
{\left[\mathrm{Mg} / \mathrm{m}^{3}\right]}\end{array}$ & 1.39 & 1.29 & 1.42 & 1.33 & 1.20 & 1.05 & 1.27 & 1.34 & 1.30 & 1.35 & 1.13 & 1.45 & 1.36 \\
\hline Water & 160 & 200 & 140 & 175 & 200 & 250 & 160 & 150 & 180 & 150 & 240 & 120 & 141 \\
\hline w/c & 0.8 & 0.8 & 0.7 & 0.7 & 0.5 & 0.5 & 0.4 & 0.6 & 0.6 & 0.5 & 0.6 & 0.6 & 0.47 \\
\hline
\end{tabular}

Specimens were prepared and cured according to EN-12390-2. They were demoulded after 2 days and then water-cured in the laboratory until age of 28 days. The workability of concrete mixtures was measured by flow table test, in accordance with EN 12350-5. Standard mixing was used in these tests. It is likely that the use of the proposed by Tam, Gao and Tam two stage mix approach can give better results for series with RCA contribution [21]. Interfacial transition zone (ITZ) has slightly higher $w / c$ ratio than the rest of the concrete so by using this two stage mixing approach which consists in dividing the mixing process into two stages of adding water better results in strengthen the ITZ between RCA and new cement paste may be obtained [22].

\subsection{Performed tests}

Both compressive and tensile strength of concrete were determined using ToniTechnik ToniPACT II compression machine with $3000 \mathrm{kN}$ capacity. The rate of loading was maintained at $0.5 \mathrm{MPa} / \mathrm{s}$ for compressive strength test and $0.05 \mathrm{MPa} / \mathrm{s}$ for tensile splitting 
strength test. The tests were conducted on $150 \mathrm{~mm}$ cube specimens after 28 days of hardening.

Sorptivity test was conducted by mass method on halves of $150 \mathrm{~mm}$ cubic specimens obtained from tensile splitting test. Free water absorption was also determined before the sorptivity test was performed. First, the specimens had been weighed in the fully saturated state and then oven dried at the temperature of about $105^{\circ} \mathrm{C}$ to permanent mass and once again weighed. Then the specimens were left to cool down to ambient temperature of about $20 \pm 1^{\circ} \mathrm{C}$ at which the sorptivity test was conducted. The oven dried and weighed specimens were dipped up to the depth of approximately $3 \mathrm{~mm}$ in a container with distilled water. The specimens were then weighed in particular time intervals to get their weight gain resulting from water sorption. The test lasted 6 hours. Sorptivity expressed in $\mathrm{g} /\left(\mathrm{cm}^{2} \cdot \mathrm{h}^{0.5}\right)$ was calculated as a slope of the linear function expressing the dependence of the mass of the water absorbed by the area on the time. This relationship is expressed by the formula (1) in which $\Delta m$ is the mass of water absorbed [g], $A_{\mathrm{s}}$ is the area of the water ingress $\left[\mathrm{cm}^{2}\right], S$ is the sorptivity value $\left[\mathrm{g} / \mathrm{cm}^{2} \cdot \mathrm{h}^{0.5}\right]$ and $t$ is the time of the water ingress $[\mathrm{h}]$.

$$
\Delta m / A_{\mathrm{s}}=S \cdot t^{0.5}
$$

\section{Results and discussion}

Results of the performed tests are presented in the Table 3 and 4. Except the consistency flow table test, for which three measurements were made, each value presented in the tables is the average of ten measurements.

\subsection{Flow}

The results of the flow table test are very ambiguous. In the Table 3 there are listed, among others, percentage differences of the flow values between concrete mixtures with RCA and natural aggregate. A negative value means a lower value of the flow of the concrete with RCA. Values of calculated flow differences are both positive and negative. The average difference calculated on the basis of the average values of the flow of the both types of mixtures is $3.2 \%$. However, the range of results is in the case of negative values from $-1.4 \%$ to $-23.4 \%$, and in the case of positive values from $8.5 \%$ to $30.2 \%$.

As it can be seen, it is impossible to indicate any trend in the results obtained. They cannot be linked in any way neither to the values of $\mathrm{w} / \mathrm{c}$ of the mixtures nor to the amount of cement. This is probably the result of a significant variation in the water absorbability of the used RCA. Despite the determination of this value and inclusion of additional water in the recipe, the amount of which depends on the mass of the RCA, the differences in the flow value of the mixtures are still very diverse.

\subsection{Compressive and tensile strength}

The use of RCA in each case resulted in reduction of compressive strength of the concrete by an average of $13.5 \%$ (compared to mixtures in which only natural aggregate was used). These differences ranged from $0.5 \%$ for the " 6 " series to $29.3 \%$ for the " 3 " series. It seems clear that with the increase of the $\mathrm{w} / \mathrm{c}$ ratio, the difference in the compressive strength are increasing. The compression strength reduction for the series with $\mathrm{w} / \mathrm{c}>0.6$ ranged from 15 to $30 \%$, while for the series with $w / c<0.6$ it did not exceed $17 \%$.

In contrast to compressive strength in the case of four series concrete with RCA achieved higher tensile strength the same mixtures with natural aggregate. The differences 
are not very high (from $1.9 \%$ to $6.4 \%$ ) and are in most cases lower than the measurement uncertainty. The results indicate that the use of RCA in concrete used for making structural elements, of classes higher than $\mathrm{C} 16 / 20$, does not lead to a radical decrease in both compression and tensile strength values.

Table 3. Flow and mechanical properties test results

\begin{tabular}{|c|c|c|c|c|c|c|c|c|c|}
\hline \multirow[b]{2}{*}{$\begin{array}{c}\text { Series } \\
\text { number }\end{array}$} & \multicolumn{3}{|c|}{ Flow } & \multicolumn{3}{|c|}{ Compressive strength } & \multicolumn{3}{|c|}{ Tensile strength } \\
\hline & $\begin{array}{c}\mathrm{N} \\
\text { series } \\
{[\mathrm{cm}]}\end{array}$ & $\begin{array}{c}\mathbf{R} \\
\text { series } \\
{[\mathrm{cm}]}\end{array}$ & $\begin{array}{l}\text { Diff. } \\
{[\%]}\end{array}$ & $\begin{array}{c}\mathbf{N} \\
\text { series } \\
{[\mathrm{MPa}]}\end{array}$ & $\begin{array}{c}\mathbf{R} \\
\text { series } \\
{[\mathrm{MPa}]}\end{array}$ & $\begin{array}{l}\text { Diff. } \\
{[\%]}\end{array}$ & $\begin{array}{c}\mathrm{N} \\
\text { series } \\
{[\mathrm{MPa}]}\end{array}$ & $\begin{array}{c}\mathbf{R} \\
\text { series } \\
{[\mathrm{MPa}]}\end{array}$ & $\begin{array}{l}\text { Diff. } \\
\text { [\%] }\end{array}$ \\
\hline 1 & 41.9 & 39.8 & -5.0 & 20.5 & 16.4 & -20.0 & 1.92 & 1.59 & -17.2 \\
\hline 2 & 56.6 & 66.4 & 17.3 & 20.1 & 14.6 & -27.4 & 1.94 & 1.31 & -32.5 \\
\hline 3 & 47.2 & 40.6 & -14.0 & 23.9 & 16.9 & -29.3 & 2.1 & 1.52 & -27.6 \\
\hline 4 & 39.7 & 46.3 & 16.6 & 27.7 & 23.5 & -15.2 & 2.27 & 2.04 & -10.1 \\
\hline 5 & 53.3 & 57.9 & 8.6 & 45.9 & 42.6 & -7.2 & 3.08 & 3.15 & 2.3 \\
\hline 6 & 60.1 & 67.2 & 11.8 & 42.5 & 42.3 & -0.5 & 3.08 & 3.04 & -1.3 \\
\hline 7 & 43.3 & 34.8 & -19.6 & 58.5 & 54.8 & -6.3 & 3.63 & 3.25 & -10.5 \\
\hline 8 & 47.5 & 36.4 & -23.4 & 31.4 & 28.4 & -9.6 & 2.5 & 2.39 & -4.4 \\
\hline 9 & 42.1 & 54.8 & 30.2 & 35.8 & 30.2 & -15.6 & 2.71 & 2.32 & -14.4 \\
\hline 10 & 36.7 & 36.2 & -1.4 & 44.6 & 37.2 & -16.6 & 2.71 & 2.8 & 3.3 \\
\hline 11 & 62.4 & 69.8 & 11.9 & 28 & 27.4 & -2.1 & 2.2 & 2.34 & 6.4 \\
\hline 12 & 45.8 & 42.8 & -6.6 & 28.7 & 24.1 & -16.0 & 2.28 & 1.91 & -16.2 \\
\hline 13 & 37.6 & 40.8 & 8.5 & 40.8 & 38.2 & -6.4 & 2.7 & 2.75 & 1.9 \\
\hline Average & 47.2 & 48.7 & 3.2 & 34.5 & 30.5 & -11.6 & 2.55 & 2.34 & -8.2 \\
\hline
\end{tabular}

\subsection{Water absorption and sorptivity}

RCA is characterized by much higher absorbability than natural aggregate which resulted in much higher water absorption of concrete series with RCA. Only in the case of the series "6" significantly higher absorbability of concrete with sole natural aggregate was observed. In the case of the series " 11 " the difference is so small that it cannot be treated as significant.

The use of RCA makes it very hard to meet the frequently occurring condition of maximal concrete absorbability of $5 \%$. In the case of the R-series concrete, the clear relationship between water absorption and w/c ratio can be observed, for example series R2 with the highest $\mathrm{w} / \mathrm{c}$ ratio equal to 0.8 has also the highest water absorption $8.76 \%$, and the R7 series has both the lowest water absorption $5.31 \%$ and the lowest w/c ratio equal to 0.4 . This dependency is not so clear for concrete series with natural aggregate. It should be noted that high absorbability of series with RCA can be reduced by using additives such as metakaolin or silica fume [23].

The results of sorptivity measurements confirm, that concrete with RCA achieves less favourable values of durability parameters. The lowest sorptivity was $0.101 \mathrm{~g} /\left(\mathrm{cm}^{2} \cdot \mathrm{h}^{0.5}\right)$ and was obtained in the case of the R7 concrete series and the highest value of the sorptivity was $0.245 \mathrm{~g} /\left(\mathrm{cm}^{2} \cdot \mathrm{h}^{0.5}\right)$ obtained for the R2 concrete series. The range of the sorptivity values of the concrete series with the natural aggregate was from $0.075 \mathrm{~g} /\left(\mathrm{cm}^{2} \cdot \mathrm{h}^{0.5}\right)$ (the $\mathrm{N} 12$ series) to $230 \mathrm{~g} /\left(\mathrm{cm}^{2} \cdot \mathrm{h}^{0.5}\right)$ (the N11 series). In case of the concrete series with RCA the extreme values of sorptivity corresponded well with the value of the w/c ratio and the compressive strength. 
Table 4. Durability parameters test results

\begin{tabular}{|c|c|c|c|c|c|c|}
\hline \multirow[b]{2}{*}{$\begin{array}{c}\text { Series } \\
\text { number }\end{array}$} & \multicolumn{3}{|c|}{ Sorptivity } & \multicolumn{3}{|c|}{ Water absorption } \\
\hline & $\begin{array}{c}\mathbf{N} \\
\text { series } \\
{\left[\mathrm{cm} / \mathbf{h}^{0.5}\right]}\end{array}$ & $\begin{array}{c}\mathrm{R} \\
\text { series } \\
{\left[\mathrm{cm} / \mathbf{h}^{0.5}\right]}\end{array}$ & $\begin{array}{l}\text { Diff. } \\
{[\%]}\end{array}$ & $\begin{array}{c}\mathbf{N} \\
\text { series } \\
{[\%]}\end{array}$ & $\begin{array}{c}\mathrm{R} \\
\text { series } \\
{[\%]}\end{array}$ & $\begin{array}{l}\text { Diff. } \\
\text { [\%] }\end{array}$ \\
\hline 1 & 0.104 & 0.194 & 86.5 & 5.05 & 7.42 & 46.9 \\
\hline 2 & 0.142 & 0.245 & 72.5 & 4.85 & 8.76 & 80.6 \\
\hline 3 & 0.078 & 0.179 & 129.5 & 5.20 & 6.86 & 31.9 \\
\hline 4 & 0.133 & 0.193 & 45.1 & 5.34 & 6.81 & 27.5 \\
\hline 5 & 0.117 & 0.162 & 38.5 & 5.23 & 7.00 & 33.8 \\
\hline 6 & 0.176 & 0.162 & -8.0 & 8.41 & 7.35 & -12.6 \\
\hline 7 & 0.080 & 0.101 & 26.3 & 4.47 & 5.31 & 18.8 \\
\hline 8 & 0.140 & 0.144 & 2.9 & 5.50 & 6.15 & 11.8 \\
\hline 9 & 0.121 & 0.155 & 28.1 & 5.62 & 6.74 & 19.9 \\
\hline 10 & 0.090 & 0.114 & 26.7 & 4.88 & 5.99 & 22.7 \\
\hline 11 & 0.230 & 0.198 & -13.9 & 8.71 & 8.66 & -0.6 \\
\hline 12 & 0.075 & 0.142 & 89.3 & 3.25 & 5.69 & 75.1 \\
\hline 13 & 0.100 & 0.108 & 8.0 & 5.10 & 5.35 & 4.9 \\
\hline Average & 0.122 & 0.161 & 32.0 & 5.51 & 6.78 & 23.0 \\
\hline
\end{tabular}

\section{Conclusions}

As a result of the research, it can be noticed that the use of RCA in the amount of $50 \%$ of the total coarse aggregate mass does not cause very high reduction of both mechanical and some durability properties. It can be also stated that it is possible to obtain the high quality concrete with use of RCA. The good example is the R7 concrete series which has the average compressive strength of $54.8 \mathrm{MPa}$, the sorptivity value of $0.101 \mathrm{~g} /\left(\mathrm{cm}^{2} \cdot \mathrm{h}^{0.5}\right)$ and the free water absorption slightly exceeding $5 \%$, which allows to name this concrete series as high-quality concrete.

Using RCA as 50\% of total coarse aggregate mass resulted in average reduction in compressive and tensile strength by $11.6 \%$ and $8.2 \%$ respectively. Deterioration of the measured durability parameters of the concrete was much higher - the sorptivity increased on average by $32.0 \%$, and the absorption by $23.0 \%$. It should be noted however that the differences resulting from the use of RCA decreased with the increase of the strength of the concrete. Analysing the concrete series with the compressive strength higher than $25 \mathrm{MPa}$ (obtained for concrete without RCA), the average increase of sorptivity was only $17.2 \%$.

The results do not exclude the usage of concrete with RCA for structures exposed to unfavourable environmental conditions, although in such cases special care should be taken and the low w/c ratio $(0.4-0.5)$. As it can be seen in case of the concrete with RCA the key parameter which greatly influences the durability parameters is w/c ratio. And in the case of concrete with natural aggregate more important is the amount of cement which decides of the volume share of the more porous matrix. The w/c ratio also plays an important role but it is a little less important. It is also highly recommended to perform appropriate tests of durability parameters before using RCA in concrete preparation. 
The obtained results indicate the legitimacy of undertaking further research, including other properties such as depth of carbonation, migration of chlorides and others. It is also worth considering the idea of carrying out research on a partly carbonated RCA.

\section{References}

1. Giergiczny Z., Budownictwo, Technol. Archit. 3(39), 44-48 (2007)

2. E. Özbay, M. Erdemir, H. I. Durmuş, Constr. Build. Mater. 105, 423-434 (2016)

3. W. Qiang, Y. Peiyu, F. Jingjing, Mag. Concr. Res. 65, 2, 71-81 (2013)

4. M. J. McGinnis, M. Davis, A. de la Rosa, B. D. Weldon, Y. C. Kurama, Mag. Concr. Res. 69, 23, 1203-1211 (2017)

5. B. Zegardło, P. Ogrodnik, J. Szulej, Logistyka 4/2015, 6993-7004 (2015)

6. L. Czarnecki, H. Justnes, Cem. Wapno Bet. 6, 341-362 (2012)

7. Annual Review 2016-2017 (European Aggregate Association, 2017)

8. K. P. Verian, N. Whiting, J. Olek, J. Jain, M. Snyder, "Using Recycled Concrete as Aggregate in Concrete Pavements to Reduce Materials Cost," 2013

9. E. Vázquez, M. Barra, D. Aponte, C. Jiménez, S. Valls, Constr. Build. Mater. 67, 6167 (2014)

10. W. Kubissa, R. Jaskulski, M. Brodnan, Period. Polytech. Civ. Eng. 60, 4, 583-590 (2016)

11. J. De Brito, J. Ferreira, J. Pacheco, D. Soares, M. Guerreiro, J. Build. Eng. 6, 1-16 (2016)

12. R. Jaskulski, O. A. Waszak, W. Kubissa, Procedia Eng. 153, 240-247 (2016)

13. R. Jaskulski, W. Kubissa, P. Koteš, M. Brodňan, MATEC Web Conf. 117, 1-8 (2017)

14. A. Ajdukiewicz, A. Kliszczewicz, Cem. Concr. Compos. 24, 2, 269-279 (2002)

15. N. Y. Ho, Y. P. K. Lee, W. F. Lim, K. C. Chew, G. L. Low, S. K. Ting, Mag. Concr. Res. 67, 12, 633-644 (2015)

16. W. Kubissa, R. Jaskulski, P. Reiterman, J. Renew. Mater. 5, 1, 53-61 (2017)

17. D. Xuan, B. Zhan, C. S. Poon, Cem. Concr. Compos. 65, 67-74 (2016)

18. J. Zhang, C. Shi, Y. Li, X. Pan, C. S. Poon, Z. Xie, Constr. Build. Mater. 98, 1-7 (2015)

19. L. Zhu, J. Dai, G. Bai, F. Zhang, Constr. Build. Mater. 94, 620-628 (2015)

20. R. Jaskulski, P. Reiterman, W. Kubissa, in Energy Effic., Sustain. Build. Mater. Prod.283-302, I. Hager, Ed. (Politechnika Krakowska, Kraków, 2017)

21. V. V. W. Y. Tam, X. F. X. Gao, C. C. M. Tam, Cem. Concr. Res. 35, 6, 1195-1203 (2005)

22. K. L. Scrivener, A. K. Crumbie, P. Laugesen, Interface Sci. 12, 4, 411-421 (2004)

23. W. Kubissa, B. Pacewska, I. Wilińska, Adv. Mater. Res. 1054, 154-161 (2014) 